\title{
Interrelations of paranormal and pseudoscientific beliefs and critical thinking disposition among undergraduate medical students of RSU
}

\author{
Arturs Utinans ${ }^{1}$, Gunta Ancane $^{1}$, Anita Villerusa $^{2}$, and Janis Vetra ${ }^{3}$ \\ ${ }^{1}$ Department of Psychosomatic Medicine and Psychotherapy, Rīga Stradinš̌ University, Latvia \\ ${ }^{2}$ Department of Public Health and Epidemiology, Rīga Stradinš̌ University, Latvia \\ ${ }^{3}$ Department of Morphology, Rīga Stradinš̌ University, Latvia
}

\begin{abstract}
Magical and paranormal beliefs have been found in all cultures and strata of society, including medical university students. Critical thinking skills and dispositions are generally considered desirable outcomes of the educational process. Nevertheless, there is the lack of conceptual clarity about interrelations between the magical and critical thinking. Aim of the study is to explore prevalence of magical, paranormal beliefs and pseudoscientific beliefs among undergraduate medical students, as well as to explore prevalence of critical thinking dispositions among medical students and to assess interrelations and psychodynamics between "noncritical" forms of thinking - magical, paranormal and pseudoscientific beliefs, and critical thinking disposition. The results showed statistically significant negative correlation between paranormal beliefs and critical thinking disposition if students are put in optional situation between opposite statements. If statements in assessment scales do not put respondents in optional situation, their results do not show significant correlations.
\end{abstract}

Key words: magical thinking, paranormal beliefs, pseudoscientific thinking, critical thinking disposition.

\section{Introduction}

Magical, paranormal and superstitious beliefs have been found in all cultures for thousands of years and continue to thrive in modern times in all populations, including university students despite scientific education. By "paranormal" is meant a phenomenon which, if authentic, violates a basic limiting principle of science [1]. These basic limiting principles (e.g., a mental event cannot directly cause a physical event, except for one in the person's own brain) are overwhelmingly supported by evidence from human experience and from scientific observation. Therefore magical thinking and scientific evidence based thinking are mutually exclusive.

Magical thinking (magical beliefs) has been defined as "belief and reported experiences in forms of causation that by conventional standards are invalid" [2]. According to anthropologist Dr. Philips Stevens, magical thinking involves several elements, including the belief in the interconnectedness of all things through forces and powers that transcend both physical and spiritual connections. Magical Thinking appears characteristic of those paranormal beliefs that emphasize forms of causality that violate basic limiting principles of science - for example, psi, witchcraft, superstition, spiritualism, and precognition. 
In empirical studies religious and paranormal beliefs have been both positively rated (both are beyond scientific explanation), and negatively rated (rejection of the paranormal by the official Christian doctrine) or unrelated. Religious beliefs have been noted to differ from paranormal beliefs on the grounds that faith in religious beliefs does not require empirical proof [3]. Many magical and paranormal beliefs involve interconnection and causality of material objects (animate or inanimate) with invisible, indeterminable energy, such as human mental force moving objects (telekinesis), impact of planets on human behaviour, magical chants influencing human fate and illnesses. It differs from beliefs in supernatural forces in traditional religions as gods, devils, immortal soul. However some paranormal beliefs also involve immaterial objects such as ghosts. But paranormal beliefs acknowledge possibility of objective registration, for example photography of ghosts, which differs from beliefs of impossibility to make a photo of the God. Our study defined religious and paranormal beliefs as separate because it is possible to test scientifically paranormal and magical beliefs, and because of use RPBS, where these beliefs are separated by scale author.

A construct of critical thinking based on a 1990 American Psychological Association Delphi Report defined it as a purposeful, self-regulatory judgement that gives reasoned consideration to context, evidence, concepts, methods and standards in deciding what to believe or what to do [4]. It also means being open-minded and willing to put aside personal biases, as opposed to self-deceptive and wishful thinking in paranormal believers that is characterised as narrow-minded and not striving to find the truth. The Delphi study identified a list of critical thinking dispositions that are necessary for critical thinking. Critical thinking skill is the behaviour that is influenced by critical thinking dispositions (attitudes) and a set of "facilitating factors." Critical thinking disposition describes more motivation to know the truth than critical thinking skills per se [4].

The relationship between magical thinking, belief in paranormal and critical thinking ability has been examined in the past. Weakness of rational or critical thinking in paranormal believers was found to correlate lower cognitive abilities by number of errors made on a syllogistic reasoning task [5] and in line with this research, Tobacyk (1984), as well as Messer and Griggs (1989) found that students with better marks exhibited less belief in paranormal $[6,7]$. Individuals who held strong beliefs in the paranormal scored higher on a delusional ideation measure and made more errors on a deductive reasoning task than individuals with weaker beliefs [8]. Under this view the believer in the paranormal variously is considered to be illogical (opposite to logic), irrational (opposite to rationality), credulous, uncritical (opposite to critical), and even foolish. In one study of the critical thinking ability (CTA) of 13 believers and 13 nonbelievers in paranormal phenomena it was found that sceptics showed a significantly higher level of CTA than believers and were significantly less dogmatic than believers [9]. Second study evaluated the CTA of believers and sceptics on a task dealing with the paranormal. 18 believers and 17 sceptics were asked to evaluate critically either a research article on a paranormal (psycho-kinesis) or almost identical article on not paranormal phenomenon (pain tolerance). While it was anticipated that believers would show a bias in favour of the paranormal article, results indicated that believers and nonbelievers were equally critical of the paranormal article [9]. Interrelations between thinking types remain unclear.

A few researchers have sought to relate paranormal belief to the amount of scientific education the individual has had. Students enrolled in the sciences are reported to have lower belief in the paranormal than do students of the humanities, at least in some surveys [9]. A survey of over 350 Spanish university students found a tendency for higher paranormal beliefs amongst students of tourism, and lower belief amongst students enrolled on courses in biology, sociology and physics, particularly for religious belief. Students of psychology, 
education and human resources expressed more neutral beliefs [10]. It means that exposure to the principles of scientific thinking will reduce the level of paranormal belief, however Harvey J. Irwin in his review of the empirical literature mentions Dudycha is cautious about expectation that a general program of scientific education will substantially diminish paranormal belief. That is, for education to have major impact on the level of paranormal belief, the education program may have to be geared specifically to the paranormal [11]. Dudycha found that 25 popular superstitious beliefs of the college seniors were not greatly different from those of the freshmen [12].

Critical thinking skills and dispositions are generally considered desirable outcomes of the educational process. Beliefs in the paranormal and pseudoscience may indicate a decline in scientific literacy and critical thinking, their prevalence among university students has motivated some to affirm that education in industrialized countries is not fulfilling its mission appropriately [13]. On the whole, the relationship consistently tended in the direction that believers in psi have lower critical thinking ability, but only with moderate effect size, depending on measures and conceptual foundation.

A study of the University of Vienna was conducted to assess relationships between critical thinking and belief in paranormal [14]. Study with slightly different instruments used Paranormal Belief Scale, a scale of paranormal experiences, Cornell Critical Thinking Test and the Watson-Glaser Critical Thinking Appraisal [15]. The results showed no significant correlations between critical thinking and paranormal belief or experiences. Reasoning ability had significant effect on paranormal belief scores. Subjects with lower reasoning ability scored higher on Traditional Paranormal Belief. This is in line with cognitive deficits hypothesis [14].

A study of the University of Derby predicted that experimental group - those studying parapsychology - will show decrease in paranormal beliefs (with RPBS) and an accompanying increase in critical thinking skills (with Cornell Critical Thinking Test). This will be due to the content of the module, in which claims for the paranormal are critically examined. Students will be implicitly taught evaluative and critical thinking skills. Study found that although students studying parapsychology appear to perform more poorly than those not studying parapsychology, this was not significant [16].

Other hypothesis says that magical thinking, paranormal beliefs and critical thinking can exist parallel one another in the same mind - so called 'dual process theory'. Peter Lamont wrote article where observed two equal phenomena: avowal of paranormal beliefs and turning to scepticism and avowal of prior scepticism (e.g. 'I was sceptic'), accompanied by avowal of subsequent paranormal beliefs (e.g. 'I realized that the paranormal exists after all'). Avowals of prior scepticism are common, and have been around for a long time [17]. Disavowal of prior paranormal beliefs and subsequent avowal of scepticism is taken as reparation of "cognitive deficit" and as "maturation" and open-mindedness. Yet if sceptics and believers are different types of people, if believers are more credulous or more likely to misinterpret normal events, how do we understand all these people who began as sceptics then became believers? Did their cognitive abilities decline? [17].

According to different thinking styles competition hypothesis when one thinking is activated other type of thinking is suppressed, akin to neuronal competition theory in neurosciences. Paranormal and magical beliefs do not disappear from mind by development of scientific literacy and critical thinking. There was found evidence for the independence of the two thinking styles, named dual cognition theory [18] or dual-process theory [19].

This paper describes the interrelations of two thinking types among RSU undergraduate medical students. Medical students acquire biological and neurosciences, evidence based researches, have some scientific literacy and are expected to act in a critical manner when 
Table 1. Sample items from the MIS instrument.

\begin{tabular}{|l|l|l|l|}
\hline N. & Statement & True & False \\
\hline 34. & The soul continues to exist though the body may die & 1 & 0 \\
\hline 37. & Black cats can bring bad luck & 1 & 0 \\
\hline 51. & The number "13" is unlucky & 1 & 0 \\
\hline
\end{tabular}

evaluating evidence for claim. "If medicine is an applied science, it is desirable that physicians know and understand the theoretical foundations of science, so they develop a critical mentality. This mentality is characterised by a permanent willingness to apply scientific habits of mind in a wide range of social contexts [13].

\section{Purpose and objectives}

The purpose of this exploratory study was to identify and explain prevalence and interrelations between different types of scientific and not scientific thinking in medical students. Scientific thinking was coined as critical thinking, unscientific type of thinking as magical thinking, paranormal beliefs and pseudoscientific beliefs.

The purpose the following research objectives were used to guide this study:

1. To explore prevalence of magical thinking, paranormal beliefs and pseudoscientific beliefs among medical students.

2. To explore prevalence of critical thinking dispositions between medical students.

3. To assess interrelations between unscientific forms of thinking - magical thinking, paranormal and pseudoscientific beliefs, and critical thinking disposition.

\section{Material and methods}

\subsection{Instruments}

1. The Magical Ideation Scale (Eckblad \& Chapman, 1983) is a 30-item forced-choice assessment instrument. Magical Ideation Scale contains several items concerning personal paranormal experiences such as sensing telepathy, magic, reincarnation, precognition. It is composed of 30 items in a dichotomous True/False format. Magical Ideation Scale total scores can range from 0 to 30 , with higher scores presumably indicating magical thinking (Sample items from the MIS instrument Table 1).

2. The Revised Paranormal Belief Scale (RPBS) (Tobacyk, 1988) was used to assess degree of belief in each of these dimensions (with Likert's seven-point scale ranging from 1 (strongly disagree (SD), moderately disagree (MD), slightly disagree (SD), uncertain (U) to 7 (strongly agree (SA)). Total scores can range from 26 to 182 , with lager scores reflecting greater belief. Paranormal belief subscale scores can range from 3 to 21 (in subscales with 3 items) or from 4 to 28 (in subscales with 4 items).) : Belief in Psi, Witchcraft, Superstition, Spiritualism, Extraordinary life forms, Precognition and Traditional Religious Belief. It is generally assumed that Traditional Religious Belief and Belief in Extraordinary Life Forms subscales does not indicate magical thinking or classical paranormal beliefs. Belief in Extraordinary Life Forms could be classified as pseudoscientific non-magical beliefs (Sample items from the RPBS instrument Table 2).

3. The Critical Thinking Disposition Assessment (EMI) (Moore, Rudd, \& Penfield, 2002) contains three scales (Engagement, Innovativeness, and Cognitive maturity). The Engagement disposition measured students' predisposition to look for opportunities to use 
Table 2. Sample items from the RPBS instrument.

\begin{tabular}{|c|l|c|c|c|c|c|c|c|}
\hline $\mathbf{N}$. & Statement & SD & MD & SID & U & SIA & A & SA \\
\hline 34. & The soul continues to exist though the body may die & 1 & 2 & 3 & 4 & 5 & 6 & 7 \\
\hline 37. & Black cats can bring bad luck & 1 & 2 & 3 & 4 & 5 & 6 & 7 \\
\hline 51. & The number "13" is unlucky & 1 & 2 & 3 & 4 & 5 & 6 & 7 \\
\hline
\end{tabular}

$* 1$ = Strongly Disagree (SD), 2 = Moderately Disagree (MD), 3 = Slightly Disagree (SID),

$4=$ Uncertain (U), $5=$ Slightly agree (SlA), $6=$ Moderately Agree (MA), $7=$ Strongly Agree (SA).

Table 3. Sample items from the EMI instrument.

\begin{tabular}{|l|l|c|c|c|c|c|}
\hline N. & Statement & SD & D & U & A & SA \\
\hline 62. & I am interested in many issues (Engagement) & 1 & 2 & 3 & 4 & 5 \\
\hline 70. & $\begin{array}{l}\text { I am likely to change my opinion when I am given new } \\
\text { information that conflicts with my current opinion (Cognitive } \\
\text { Maturity) }\end{array}$ & 1 & 2 & 3 & 4 & 5 \\
\hline 80. & $\begin{array}{l}\text { I search for the truth even when it makes me uncomfortable } \\
\text { (Innovativeness) }\end{array}$ & 1 & 2 & 3 & 4 & 5 \\
\hline
\end{tabular}

${ }^{*}$ Strongly Disagree (SD); Disagree (MD); Uncertain (U); Agree (MA); Strongly Agree (SA).

Table 4. Sample items from the CTDAS instrument subscale "Open-mindedness".

\begin{tabular}{|l|l|c|c|c|c|c|}
\hline N. & Statement & SD & D & U & A & SA \\
\hline 104. & I believe that changing opinions is a sign of weakness & 5 & 4 & 3 & 2 & 1 \\
\hline 106. & I do not surrender in discussions & 5 & 4 & 3 & 2 & 1 \\
\hline
\end{tabular}

*Strongly Disagree (SD); Disagree (MD); Uncertain (U); Agree (MA); Strongly Agree (SA).

reasoning; anticipating situations that require reasoning; and confidence in reasoning ability. The Innovativeness disposition measured students' predisposition to be intellectually curious and wanting to know the truth. The Cognitive Maturity disposition measured students' awareness of the complexity of real problems; being open to other points of view; and being aware of their own and others biases and predispositions (Sample items from the EMI instrument Table 3).

4. The Critical Thinking Disposition Additional Scales (CTDAS) - was created by RSU researchers group. It contain subscales "Truth seeking", "Open-Mindedness" (terms are similar to two California Critical Thinking Disposition Inventory subscales (Facione ET AL., 1996), but with different statements).

This scale was called "Additional" because instrument was not intended to use alone as reliable measure of critical thinking disposition. Additional scales were intended to put respondents in a more optional situation between mutually exclusive alternatives in order to find the truth. These two terms were chosen because, in our opinion, they express the essence of critical thinking disposition most precisely. Seeking is more important than attachment to a particular theory or authority (spiritual or any other). In the process of scientific exploration we must discard old theories. It means we need open-mindedness in our way to the truth. Belief is attachment to particular theory in spite of new opposite evidences.

Open-mindedness contains statements that express striving for new knowledge and disavowal of old opinions that contradict new facts (Sample items from the CTDAS instrument subscale "Open-mindedness" Table 4). 
Table 5. Sample items from the CTDAS instrument subscale "Truth seeking".

\begin{tabular}{|c|l|c|c|c|c|c|}
\hline N. & Statement & SD & D & U & A & SA \\
\hline 87. & $\begin{array}{l}\text { Reflections of Great Spiritual teachers outpace scientific } \\
\text { discoveries and are more truthful. }\end{array}$ & 1 & 2 & 3 & 4 & 5 \\
\hline 89. & $\begin{array}{l}\text { Beliefs of Pope, Dalai Lama, and other spiritual } \\
\text { authorities have to subjugate scientific exploration as } \\
\text { Newton's or Einstein's. }\end{array}$ & 5 & 4 & 3 & 2 & 1 \\
\hline 95. & $\begin{array}{l}\text { I believe that scientific researchers must not interfere } \\
\text { with the realm of religion. }\end{array}$ & 5 & 4 & 3 & 2 & 1 \\
\hline
\end{tabular}

*Strongly Disagree (SD); Disagree (MD); Uncertain (U); Agree (MA); Strongly Agree (SA).

Truth seeking contains statements that express readiness to apply scientific scrutiny all beliefs and theories. Statements do not contain ready answers (as in critical thinking skills tests) but willingness to seek the truth, even if it causes discomfort, and applying same principles for everything (for example, Sacred books) and for everybody (for example, spiritual authority). Instrument applies Critical thinking disposition scores not only to a paranormal belief but also to the traditional religiosity (Sample items from the CTDAS instrument subscale "Truth seeking" Table 5).

Totally in research four instruments with 120 statements were used. The respondents' sample comprised 149 subjects - undergraduate 4-th $(\mathrm{N}=124)$ and 6-th year $(\mathrm{N}=25)$ medical students from Rīga Stradinš̌ University. We chose 4-th and 6-th year students because they acquired many or most evidence based medical courses. Respondents were predominantly female $\mathrm{N}=106$; male were $\mathrm{N}=43$. Ninety nine $(n=99)$ of respondents acknowledge belonging to the religious denominations, 50 do not belong. Participants' demographics is shown in Table 6.

\subsection{Procedure}

Research was approved by Ethical committee of RSU. The translation and adaptation of three scales (MIS, RPBS, EMI) was carried out using the "back translation procedure" following international guidelines. The English original version was translated into Latvian by a research group expert in the subject matter. Text redactor corrected the language. This version was then translated into English by another expert - English translator. Finally both English versions (original and translated) were compared. "Back translated" versions were also sent to scale authors for comparison and approval.

The sample comprised 149 subjects - undergraduate 4-th $(\mathrm{N}=124)$ and 6-th year $(\mathrm{N}=25)$ medical students from Rīga Stradinsš University in October-November, 2012. We chose 4-th and 6-th year students because they acquired many or most evidence based medical courses. All questionnaires were filled appropriately. Respondents were predominantly female $\mathrm{N}=106$; male were $\mathrm{N}=43.99$ of respondents acknowledge belonging to the religious denominations, 50 do not belong. The mean age of the students was 23.0 (SD 1,7).The administration of questionnaires was carried out collectively in groups of 12-20 participants. The participants were previously informed about the nature of the study, as well as of their voluntary and confidential participation. All subjects completed a measure of Magical Ideation, Revised Paranormal Belief and Critical Thinking Disposition scales (EMI and CTDAS) together in one paper. The scales were administered in the classroom under our supervision to prevent students from interacting with each other and thus introducing bias into the study. Average completion took about 25-35 minutes. 
Table 6. Demographics.

\begin{tabular}{|l|r|r|}
\hline & Count & Percent \\
\hline Gender: & 106 & 71.1 \\
Female & 43 & 28.9 \\
Male & & \\
\hline Year of study: $*$ & 124 & 83.8 \\
4-th & 124 & 83.8 \\
6-th & 4 & 2.7 \\
1-th year of residency & & \\
\hline Relationships: & 11 & 7.5 \\
Married & 45 & 30.6 \\
Unmarried, have friend & 91 & 61.9 \\
Single & & \\
\hline Acquired secondary education: $*$ & 62 & 41.9 \\
Capital city & 52 & 35.1 \\
State cities & 31 & 20.9 \\
Provincial town & 2 & 1.4 \\
Rural school & 1 & 0.7 \\
Foreign country school & & \\
\hline Previous medical education*** & 8 & 5.5 \\
Yes & 137 & 94.5 \\
No & & \\
\hline Belongs to religious confession: *** & 99 & 67.8 \\
Yes & 47 & 32.2 \\
No & & \\
\hline
\end{tabular}

*One respondent did not answer the question $(n=148)$.

**Two respondents did not answer the question $(n=147)$.

$* * *$ Three respondents did not answer the question $(n=146)$.

$* * * *$ Four respondents did not answer the question $(n=145)$.

The mean age of the students was 23.0 (SD 1,7).

Data were analyzed using the SPSS for Windows statistical package. Scores (in MIS '0' or ' 1 '; RPBS from ' 1 ' to '7'; EMI and CTDAS from ' 1 'to '5') were counted and mean scores calculated for each scale and each subscale.

Reliabilities (Cronbach Alpha coefficients) were calculated for all scales. Alpha was 0.51 for MIS, 0.90 for RPBS, 0.87 for EMI, 0.67 for CTDAS, which are valid.

\section{Results}

\subsection{Prevalence of magical, paranormal and pseudoscientific beliefs between undergraduate medical students}

The MIS mean score for the total sample was 9.7 ( $\mathrm{SD}=0.3$ ). The mean score on the RPBS was $2.7(\mathrm{SD}=0.7)$. (Table 7) Students showed highest mean score on traditional religiosity subscale (4.2), which was above the middle point (4 for this scale). From the paranormal beliefs medical students showed highest results on Witchcraft and Psi beliefs subscales, what was below the average point 4 (Table 7). 
Table 7. Descriptive statistics.

\begin{tabular}{|l|c|c|r|r|}
\hline Scale & Mean & SD & Min & Max \\
\hline MIS & 9.7 & 0.3 & 0.0 & 19.0 \\
\hline RPBS & 2.7 & 0.7 & 37.0 & 157.0 \\
\hline Superstitions & 2.2 & 1.2 & 1.0 & 6.7 \\
\hline Spiritualism & 3.1 & 1.2 & 1.0 & 6.5 \\
\hline Extraordinary life forms & 3.2 & 1.1 & 1.0 & 7.0 \\
\hline Precognition & 3.2 & 1.2 & 1.0 & 6.8 \\
\hline Psi beliefs & 3.4 & 1.3 & 1.0 & 7.0 \\
\hline Witchcraft & 3.5 & 1.3 & 1.0 & 7.0 \\
\hline Religiosity & 4.2 & 1.4 & 1.0 & 7.0 \\
\hline EMI & 3.8 & 0.4 & 2.7 & 4.8 \\
\hline Innovativeness & 3.8 & 0.5 & 2.4 & 5.0 \\
\hline Engagement & 3.8 & 0.5 & 2.5 & 4.9 \\
\hline Cognitive Maturity & 3.8 & 0.4 & 2.6 & 4.8 \\
\hline CTDAS & 3.5 & 0.4 & 2.6 & 4.5 \\
\hline Truth seeking & 3.2 & 0.5 & 1.9 & 4.5 \\
\hline Open - mindedness & 3.4 & 0.4 & 2.3 & 4.4 \\
\hline
\end{tabular}

Table 8. Pearson correlation between critical thinking disposition scales: EMI and CTDAS.

\begin{tabular}{|l|c|c|l|}
\hline Scale & Truth seeking & Open-mindedness & CTDAS \\
\hline EMI & 0.119 & $0.208^{*}$ & $0.206^{*}$ \\
\hline Innovativeness & 0.074 & $0.163^{*}$ & 0.149 \\
\hline Engagement & 0.077 & 0.150 & 0.144 \\
\hline Cognitive maturity & $0.180^{*}$ & $0.252^{* *}$ & $0.271^{* *}$ \\
\hline
\end{tabular}

*Correlation is significant at the 0.05 level.

** Correlation is significant at the 0.01 level.

\subsection{Prevalence of Critical thinking disposition scores}

The EMI mean score for the total sample was $3.8(\mathrm{SD}=0.4)$. CTDAS mean score was 3.5 $(\mathrm{SD}=0.4)$. Both mean scores showed result above the midpoint score 3. CTDAS min and max scores (2.6 and 4.5) was lower than EMI min and max scores (2.7 and 4.8) despite the similar topic (critical thinking disposition) and the same amount of scoring dimensions (five)(Table 7).

The Innovativeness subscale of EMI, which includes also truth seeking dimension, did not show significant correlation with the Truth Seeking subscale of CTDAS $(0.073 ; p=0.374)$, and showed positive correlation with the Open-Mindedness subscale of CTDAS (0.163; $p=0.046$ ). (Table 8).

It means that average respondent in CTDAS had chosen more in direction to believing spiritual authorities and less in the direction of truth seeking and critical thinking. Only the Cognitive Maturity subscale of EMI showed positive statistically significant correlation with CTDAS $(0.271 ; p=0.001)$, Open-Mindedness subscale $(0.252 ; p=0.002)$ and slightly positive correlation with truth seeking subscale $(0.180 ; p=0.028)$. 
Table 9. Pearson correlation between magical thinking, paranormal beliefs and critical thinking disposition scores.

\begin{tabular}{|l|r|r|r|l|c|}
\hline Scale & Innovativeness & Engagement & $\begin{array}{l}\text { Cognitive } \\
\text { maturity }\end{array}$ & $\begin{array}{l}\text { Truth } \\
\text { seeking }\end{array}$ & $\begin{array}{c}\text { Open- } \\
\text { mindedness }\end{array}$ \\
\hline MIS & -0.033 & -0.074 & -0.037 & -0.135 & -0.123 \\
\hline RPBS & 0.074 & 0.014 & 0.049 & $-0.421^{* *}$ & -0.069 \\
\hline Superstitions & -0.091 & -0.079 & $-0.166^{*}$ & $-0.350^{* *}$ & -0.154 \\
\hline Spiritualism & 0.159 & 0.066 & $0.200^{*}$ & $-0.252^{* *}$ & 0.056 \\
\hline Extraordinary life forms & 0.101 & 0.089 & -0.024 & -0.025 & -0.047 \\
\hline Precognition & -0.021 & -0.025 & -0.037 & $-0.318^{* *}$ & -0.094 \\
\hline Psi beliefs & 0.125 & 0.063 & 0.132 & $-0.223^{* *}$ & -0.049 \\
\hline Witchcraft & 0.081 & 0.061 & 0.019 & $-0.340^{* *}$ & -0.005 \\
\hline Religiosity & -0.028 & -0.102 & -0.014 & $-0.416^{* *}$ & -0.071 \\
\hline
\end{tabular}

*Correlation is significant at the 0.05 level.

** Correlation is significant at the 0.01 level.

\subsection{Interrelations between "noncritical" thinking (magical thinking, paranormal and pseudoscientific beliefs), and critical thinking disposition}

MIS results did not demonstrate statistically significant correlation with any of critical thinking disposition scale (Table 9).

Truth seeking subscale from CTDAS showed statistically significant negative correlations with all RPBS all subscales except one subscale - belief in extraordinary life forms. These results show diminished tendency to seek the truth in medical students. Results reiterate findings in other universities researches about truth seeking.

The study did not find significant correlations between EMI scales and magical thinking and paranormal belief scales. Theoretically respondents could get high scores in both directions: critical thinking disposition and magical thinking/paranormal believing.

\section{Discussion}

In this study Latvian medical students showed higher belief in paranormal in comparing with University students in USA. Mean score is higher to compare with, for example, US college students' magical ideation mean scores (7.3) in Tobacyk, J., Milford, G. research [15]. It shows higher level of pagan beliefs between Latvian medical students comparing with US nonmedical students $[6,11,15]$. Probably there is a need for discussions, how students see interactions between science, pseudoscience and paranormal beliefs. Students showed highest mean score on traditional religiosity subscale (4.2), which was above the middle point (4 for this scale). This result, however, is lower in comparing, for example, with University students scores (6.3) in the Southern United States in Tobacyk J., Milford, G. research [15]. From the paranormal beliefs medical students showed highest results on Witchcraft and Psi beliefs subscales, what was below the average point 4 (Table 7). However, scores are higher in comparing with research of University students in the Southern United States.

In our study males were underrepresented and it was not possible to compare paranormal and pseudoscientific beliefs between males and females with some scientific validity. In the presented research the MIS and RPBS scores did not show any significant positive or negative correlations with EMI. The EMI Cognitive Maturity subscale shows weak 
negative correlation with Superstition subscale of RPBS $(r=-0.166 ; p=0.042)$ and slightly positive correlation with Spirituality subscale of RPBS $(r=0.200 ; p=0.015)$. From these results one can make conclusion that there are not interrelationships between magical and critical thinking types as it shows other similar studies [9, 14], although some other studies show slight correlation of paranormal beliefs and critical thinking [15], reasoning errors [5] or lower college grade points on average [6]. Probably it is possible to describe such state of mind as split - one thinking style being more consciously and the other more unconsciously. Both thinking types exist parallel, possibly, in split off manner, where one result does not affect the other. Such kind of findings supports dual-processing theory and denies theory, where critical or rational thinking develops from irrational thinking types $[17,18]$.

In situations, when a respondent must choose between incompatible statements, one tendency (for example, paranormal belief) suppresses the other (truth seeking). Either respondent have to acknowledge preference of spiritual authority statement or preference of scientific fact. Some respondents who get higher scores in EMI $(\min =2.7$; mean $=$ 3.8 ; $\max =4.8$ ), in an optional situation give preference to paranormal or pseudoscientific belief and get lower critical thinking disposition scores in CTDAS $(\min =2.6$; mean $=3.5$; $\max =4.5$ ). For example, innovativeness subscale (with truth seeking dimension) of EMI did not show statistically significant correlation with truth seeking subscale of CTDAS ( $r=0.073 ; p=0.374)$. This finding supports neuronal circuit competition theory. When social environment presses to choose one option, one thinking type takes over the other.

In the same way truth seeking subscale showed statistically significant negative correlation with RPBS all subscales, except belief in extraordinary life forms. Results could mean that the greater belief in paranormal, the less critical thinking disposition and vice versa. In some way it approves the psychodynamic and the thinking styles competition hypotheses when one thinking type is activated other type of thinking is suppressed, but both thinking types could coexist in one mind.

Nevertheless results did not show any statistically significant correlation between MIS and any of the critical thinking disposition scales, either EMI or CTDAS. Possibly, because MIS measures more paranormal or unusual experiences rather than cognitive beliefs, and these perceptual-affective states exist in a more split state from cognitive forms. Respondents, who are prone to paranormal experiences, could be more independent on beliefs of spiritual authorities (as in example of relations between mystics and church), but respondents with paranormal and magical beliefs could be more prone to incorporate cognitively what authorities used to say. Respondents with unusual experiences, like in MIS statement "I sometimes have a feeling of losing or gaining energy when people look at me or touch me", could be prone to explore these experiences in order to gain the truth. It does not mean that they interpret experience as paranormal, for example - stealing energy by vampire.

Study shows reality that critical thinking disposition and seeking the evidence based knowledge are less than it needs to be in a university of natural sciences. Study shows strength of the persistence of paranormal beliefs in human mind, even in the face of higher scientific education. This study did not make comparison between medical students and students of other faculties in Latvia, such as social or humanitarian. Such comparison needs further research. Potential limitations of the study are a well-known problem with questionnaires. Respondents consciously and unconsciously present socially desirable answers. Most people want present positive image of themselves and it could distort results and explain low Cronbach Alpha coefficients 0.51 for MIS and 0.67 for CTDAS, which nevertheless are valid. Our study did not show unconscious dispositions 
in magical thinking. There is a need for experimental methods to find such unconscious dispositions.

\section{Conclusions}

Our results show average level of magical and paranormal beliefs, as well as pseudoscientific beliefs. Mean scores are higher when comparing with beliefs in paranormal USA University students. Most undergraduate medical students belong to religious denominations (66.4\%) and got more scores in Traditional Religiosity subscale than in any of the paranormal belief subscales. This study replicated many others in which students got fewer scores in Truth Seeking subscales. Some paranormal, magical beliefs and critical thinking disposition states coexist in the minds of students.

The results showed that there is statistically significant negative correlation between paranormal beliefs and critical thinking disposition if students are put in choosy situation between opposite statements. In this situation, thinking styles started to conflict or compete with each other. If statements in assessment scales do not put respondents in optional situation, their results do not show significant correlations. It supports dual-process theory where both thinking types exist in parallel form and without environmental confrontation do not conflict. It means that to conflict, to compete or to exist parallel depends on the environmental impact.

\section{References}

[1] C.D. Broad, Philosophy 24, 291-309 (1994)

[2] M. Eckblad, L.J. J. Consulting and Clinical Psychology 51(2), 215-225 (1983)

[3] K. Aarnio, Paranormal, superstitious, magical, and religious beliefs, Unpublished dissertation. Available: http://www.doria.fi/bitstream/handle/10024/15177/ paranorm.pdf

[4] P. Facione, Critical thinking: A statement of expert consensus for purposes of educational assessment and instruction. Research findings and Recommendations (Millbrae, CA: California Academic Press, 1990)

[5] M. Wierzbicky, J. Soc. Psychol. 125, 489-494 (1985)

[6] J. Tobacyk, Psychol. Rep. 54, 217-218 (1984)

[7] W.S. Messer, R.A. Griggs, Teaching of Psychology 16, 187-191 (1989)

[8] E. Lawrence, E. Peters, J. Ner. Mental Diseases 192, 727-733 (2004)

[9] J.E. Alcock, L.P. Otis, Psychological Rep. 46(2), 479-482 (1980)

[10] L. Diaz-Vilela, C.L. Alvarez-Gonzalez, J. Parapsychology 68, 405-421 (2004)

[11] H.J. Irwi, J. A. Soci. Psychical Res., January 87, N1 (1993). Available www.aiprinc.org/para-ac05_Irwin_1993.pdf.

[12] G.J. Dudycha, J. Abnormal and Social Psychology 27(4), 457 - 464 (1933)

[13] A. Pena, O. Paco, Med. Educ. Online [serial online] 9:4 (2004). Available: http://www.med-ed-online.org.

[14] A. Hegrovic, M. Arendacy, Personality and Individual Differences 38, 1805-1812 (2005)

[15] J. Tobacyk, G. Milford, J. Personality and Social Psychology 44(5), 1029-1037 (1983)

[16] S. Croker, E. Stupple, R. Knibb, K. Silber, Paranormal belief, magical thinking \& critical thinking, unpublished poster, (2007). Available: www.derby.ac.uk/files/steve_ croker_-_paranormal_belief_magical_thinking_amp_critical_thinking.pdf 
[17] P. Lamont. Theory \& Psychology 17(5), 681-696 (2007). Available: http://tap.sagepub.com/content/17/5/681

[18] C. Witteman, J. van den Berchen, L. Claes, A. Godoy, Eur. J. Psychological Assessment 25(1), 39-47 (2009)

[19] J.S.B.T. Evans, Trends in Cognitive Science 7, 454-459 (2003) 